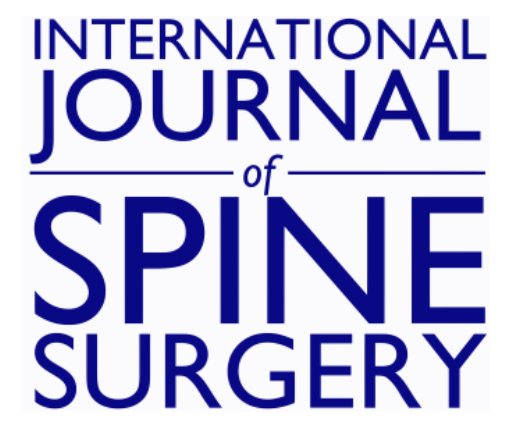

\title{
Systematic Review of Thigh Symptoms after Lateral Transpsoas Interbody Fusion for Adult Patients with Degenerative Lumbar Spine Disease
}

Isaac D. Gammal, Jeffrey M. Spivak and John A. Bendo

Int J Spine Surg 2015, 9 ()

doi: https://doi.org/10.14444/2062

http://ijssurgery.com/content/9/62

This information is current as of April 25, 2023.

Email Alerts Receive free email-alerts when new articles cite this article. Sign up at:

http://ijssurgery.com/alerts

The International Journal of Spine Surgerhthttp://ijssurgery.com/ by guest on April 25, 2 2397 Waterbury Circle, Suite 1,

Aurora, IL 60504, Phone: +1-630-375-1432

(C) 2015 ISASS. All Rights Reserved. 


\section{Systematic Review of Thigh Symptoms after Lateral Transpsoas Interbody Fusion for Adult Patients with Degenerative Lumbar Spine Disease}

Isaac D. Gammal, BA, Jeffrey M. Spivak, MD, John A. Bendo, $M D$

Division of Spine Surgery, Hospital for Joint Diseases, NYU Langone Medical Center, New York, NY

\section{Abstract}

Background

Lateral transpsoas interbody fusion (LTIF) is a minimally invasive technique for achieving lumbar spinal fusion. While it has many advantages over open techniques it carries with it a distinct set of risks, most commonly postoperative ipsilateral thigh pain, weakness and sensory disturbances. It is vital for both the surgeon and patient to understand the risks for and outcomes of injury associated with this procedure. We conducted a systematic review of the literature to evaluate the incidence, risks, and long-term clinical outcomes of post-operative thigh symptoms in patients treated with LTIF.

\section{Methods}

We conducted a search of MEDLINE, EMBASE, CINAHL, Scopus, Web of Science and the Cochrane Collaboration Library, using keywords and MeSH terms, for English-language literature published through September 2014, as well as reference lists from key articles. Studies were then manually filtered to retrieve articles that met inclusion criteria. We were interested in studies that reported postoperative lower extremity symptoms after LTIF, such as pain, weakness and changes in sensation. The strength of evidence was determined based on precepts outlined by the Grades of Recommendation Assessment, Development and Evaluation Working Group (GRADE).

Results

A total of 392 articles were initially retrieved, with 24 ultimately meeting criteria for inclusion. The incidence of any post-operative thigh symptom varied, ranging as high as $60.7 \%$, with $9.3 \%$ of patients experiencing a motor deficit related to direct nerve injury. Several studies reported cases of persistent symptoms at 6 months follow up. Additionally, inclusion of the L4-5 disc space and a longer duration of surgery were both identified as risks for developing postoperative thigh symptoms.

\section{Conclusion}

The risk of postoperative thigh symptoms after LTIF is high. Thigh pain, paresthesias and weakness were the most commonly reported symptoms. While most patients' symptoms resolved by 6 months follow up, several studies reported patients with symptoms persistent as far as 12 months removed from surgery. Surgery at the L4-5 disc space and longer surgical duration place the patient at greater risk for developing postoperative and long-term thigh symptoms.

KEYWORDS: MINIMALLY INVASIVE SPINE SURGERY, LATERAL LUMBAR INTERBODY FUSION, TRANSPSOAS INTERBODY FUSION

\section{Introduction}

McAfee et al. ${ }^{1}$ first described a minimally invasive retroperitoneal approach for lumbar spinal fusion in 1998, which involved psoas muscle retraction posteriorly to expose the disc space. Unlike traditional open approaches, this approach did not require mo- bilization of abdominal contents and great vessels, avoided extensive muscle stripping and denervation, and left normal spinal stabilizing elements intact (e.g. anterior and posterior longitudinal ligaments), thus avoiding many of the complications associated with anterior and posterior approaches to spinal fusion. Following advances in this technique, Bergey et al. ${ }^{2}$ 
described the first endoscopic lateral transpsoas approach with the use of intra-operative electromyelography (EMG) to assess nerve root proximity. In 2006, Ozgur et al. ${ }^{3}$ first described the use of the now popular Extreme Lateral Interbody Fusion system (XLIF, NuVasive, Inc, San Diego, CA), which also utilizes intra-operative EMG and permits direct visualization of the disc space. This system utilizes sequential dilators of increasing diameter to traverse the psoas muscle and expose the disc space.

In light of the growing popularity of this technique, studies were undertaken to define the intrapsoas nerve anatomy and establish safe corridors for traversing the psoas muscle. ${ }^{47}$ Several surgicallyrelevant findings were reported in the literature: nerve elements course along the anterior, middle, and posterior thirds of the psoas muscle; the L2-4 nerve roots migrate anteriorly at lower levels; the sympathetic chain overlies the L1-L5 disc spaces; and the genitofemoral nerve exits at L3 and overlies the anterior third of the psoas muscle. Because of its intimate relationship with neural structures, it is not surprising that the most commonly reported postoperative complications of this approach include lower extremity sensory disturbances, motor deficits, and hip flexion weakness. With this in mind, the purpose of this review is to attempt to answer the following three clinical questions:

1. What is the incidence of lower extremity symptoms (e.g. thigh pain, hip flexion weakness, sensory and motor deficits, etc.) following lateral transpsoas interbody fusion?

2. What are the patient, disease and surgical risk factors for the development of lower extremity symptoms?

3. What are the long-term clinical consequences and outcomes for patients with postoperative lower extremity symptoms?

\section{Material and Methods}

\section{Electronic Literature Search}

We conducted a systematic search in Medline, EMBASE, CINAHL, Scopus, Web of Science and the Cochrane Collaboration Library, combining keywords and $\mathrm{MeSH}$ terms for literature published through September 2014. Our results were limited to human studies published in the English language. Search terms were identified and combined with appropriate Boolean connectors and included "lumbar spine AND lateral interbody fusion," "lateral interbody fusion AND complications," and "transpsoas interbody fusion AND complications." Reference lists from relevant articles were hand searched for articles not identified during our electronic search.

\section{Inclusion and Exclusion Criteria}

Titles, abstracts and full-text articles were screened by two independent reviewers at each stage by applying the inclusion and exclusion criteria, with disagreement settled by a third reviewer. We included articles evaluating adult patients with degenerative lumbar spine disease including, but not limited to, degenerative disc disease, acquired spondylolisthesis, scoliosis, and spinal stenosis that were treated using a lateral retroperitoneal transpsoas approach. We only included prognostic studies (Table 1).

To answer our first study question we included articles reporting postoperative complications of this procedure, specifically lower extremity pain, sensory disturbances and weakness. To answer our second study question we included articles that delineated risk factors for developing complications, specifically patient factors, disease factors, and surgical factors

\begin{tabular}{|c|c|c|}
\hline Patients & $\begin{array}{l}\text { Adults ( }>18 \text { years old) treated for: } \\
\text { Degenerative disc disease } \\
\text { Disc herniation } \\
\text { Spondylolisthesis } \\
\text { Scoliosis } \\
\text { Spinal stenosis } \\
\text { Adjacent segment disease }\end{array}$ & $\begin{array}{l}\text { Pediatric and } \\
\text { adolescent } \\
\text { Tumor } \\
\text { Infection } \\
\text { Trauma }\end{array}$ \\
\hline Intervention & $\begin{array}{l}\text { Lateral lumbar interbody fusion } \\
\text { Transpsoas interbody fusion }\end{array}$ & \\
\hline Study & $\begin{array}{l}\text { English language } \\
\text { RCT } \\
\text { Observational studies } \\
\text { Level I/II/III evidence }\end{array}$ & $\begin{array}{l}\text { Non-English } \\
\text { Review articles } \\
\text { Case reports } \\
\text { Level IV evi- } \\
\text { dence } \\
\mathrm{n}<10\end{array}$ \\
\hline Outcome & $\begin{array}{l}\text { Lower extremity pain, weakness and senso- } \\
\text { ry and motor deficits } \\
\text { Risk factors } \\
\text { Long-term outcomes }\end{array}$ & \\
\hline
\end{tabular}


from multivariate statistical analyses. To answer our third study question we included articles reporting clinical consequences of these complications, specifically time to resolution of symptoms.

Excluded from our study were articles that did not report complications, studies that included pediatric patients and studies that included patients with disease etiology of infection, trauma or tumor. We also excluded review articles, case reports and case series'. In addition, animal and cadaveric studies were excluded. The PRISMA checklist ${ }^{8}$ was used to guide reporting of this systematic review.

\section{Data Extraction}

From the included articles the following data were extracted using a standardized form: study design and purpose, patient demographics, primary diagnoses, surgical treatment, follow-up time period, follow-up rate, duration of surgery, complications, and risk factors for and long-term consequences of postoperative complications.

\section{Study Quality and Overall Strength of Body of Literature}

Levels of evidence ratings were assigned to each article independently by two reviewers using criteria set by The Journal of Bone and Joint Surgery, America Volume 9for prognostic studies and modified to delineate criteria associated with methodological quality described elsewhere. ${ }^{10}$

The overall body of evidence with respect to each clinical question was determined based on the precepts outlined by Grades of Recommendation Assessment, Development and Evaluation Working Group (GRADE) ${ }^{11}$ and recommendations made by the Agency for Healthcare Research and Quality (AHRQ). ${ }^{10}$ This system derives strength of evidence grades for each clinical question of "high," "moderate," or "low." An overall strength of "high" means that further research is unlikely to change our confidence in the estimate of effect and will not change the estimate. Overall strength of "moderate" means that further research is likely to change our confidence in the estimate of effect and may change the estimate. A grade of "low" means that further research is very likely to impact our confidence in the estimate of effect and is likely to change the estimate. ${ }^{12}$

\section{Data Analysis}

The rate of lower extremity symptoms was reported as the proportion of patients who experienced thigh or groin pain, hip flexion weakness, sensory disturbances, and motor deficits. These symptoms were either subjectively reported by patients using questionnaires or noted on detailed neurological exam. We report the cumulative incidence of postoperative lower extremity symptoms using the number of events in the numerator and the total number of patients in the denominator. The cumulative incidence of postoperative lower extremity symptoms was defined as the proportion of patients who had been free of similar symptoms at the time of index fusion and had subsequent development of these symptoms in the postoperative period. To evaluate the incidence of persistent lower extremity symptoms, we used the number of patients experiencing symptoms at 6 months follow-up in the numerator and total number of patients in the denominator. Six months was chosen as the cut-off point since transient postoperative symptoms would be expected to resolve by this point and this was the most commonly reported follow up visit among the studies reviewed.

\section{Results}

\section{Study Selection}

We identified 392 total citations from the literature search. Of these, 336 were excluded by title/abstract review, leaving 56 articles for full-text review. From these 56 articles, 32 were excluded at full-text review. Of these 32 excluded articles, 25 reported other complications including vertebral body fracture, cage subsidence and medical complications and did not report lower extremity symptoms as a complication. Five articles were excluded as review articles and case reports. One article by Bergey at al. ${ }^{2}$ described an older endoscopic technique and was also excluded. The selection process is summarized in Figure 1.

All of the remaining 24 articles provide information on the frequency of postoperative lower extremity symptoms. Of the 24 included articles, 17 are retrospective cohort studies and 7 are prospective nonran- 
domized clinical studies. Of the 17 retrospective studies, 5 were graded as level of evidence II $^{13-17}$ and 12 graded as level of evidence III. ${ }^{18-29}$ Of the 7 prospective studies, 3 were graded as level of evidence $\mathrm{I},{ }^{30-32} 3$ graded as level of evidence II, ${ }^{23,33,34}$ and one graded as level of evidence III. ${ }^{35}$ Intraoperative neuromonitoring was used in all studies with the exception of two, ${ }^{14,36}$ where its use was at the surgeon's discretion. In addition, the use of anterior plate fixation, whether via minimally invasive or open approaches, was observed in 4 studies..$^{18,19,28,37}$ Further details on the level of evidence ratings and study characteristics for each included article can be found in the supplementary materials.

What is the incidence of lower extremity symptoms after lateral transpsoas interbody fusion?

The incidence of any postoperative lower extremity symptom ranged from $0 \%$ to $60.7 \%$ (Table 2 ). The incidence of anterior thigh or groin pain ranged from 9.3\% to $43.0 \%$. The incidence of hip flexion weakness ranged from $13.6 \%$ to $30.8 \%$. It bears mentioning that many authors attributed postoperative thigh pain and hip flexion weakness to psoas manipulation during the procedure which causes an edematous reaction. ${ }^{13,21,26,31}$ Many viewed these complications as a side-effect of the procedure, rather than a true complication, and therefore did not report the incidence. The incidence of sensory changes including pares-

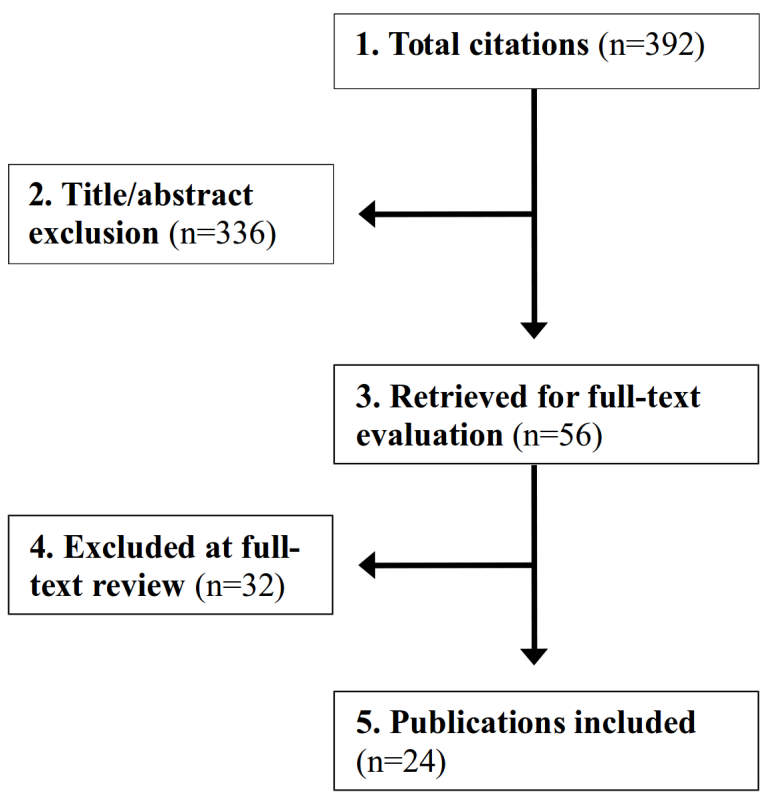

Fig. 1. Summary of study selection. thesias, dysesthesias and hypoesthesias was most frequent among all complications and ranged from 3.1\% to $60.7 \%$. This figure includes 6 cases of meralgia paraesthetica due to lateral femoral cutaneous nerve injury. ${ }^{36}$ Finally, the incidence of neurological deficit ranged from $0 \%$ to $23.9 \%$, including two cases of femoral nerve injury. ${ }^{21}$ These motor deficits resulted from direct lumbar nerve root injury, which was visualized intraoperatively and resulted in quadriceps weakness, anterior tibialis weakness and ankle dorsiflexion weakness.

What are the factors associated with increased risk of

Table 2. Studies reporting incidence of postoperative lower extremity symptoms.

\begin{tabular}{|c|c|c|c|c|c|}
\hline Author & $\begin{array}{r}\text { Population } \\
\text { size }\end{array}$ & $\begin{array}{r}\text { Anterior } \\
\text { thigh or } \\
\text { groin pain } \\
(\%)\end{array}$ & $\begin{array}{r}\text { Hip } \\
\text { flexion } \\
\text { weakness } \\
(\%)\end{array}$ & $\begin{array}{r}\text { Sensory } \\
\text { changes } \\
(\%)\end{array}$ & $\begin{array}{r}\text { Neurological } \\
\text { deficit }(\%)\end{array}$ \\
\hline $\begin{array}{l}\text { Anand et } \\
\text { al }\end{array}$ & $\mathrm{n}=12$ & - & - & $3(25.0)$ & $1(8.3)$ \\
\hline $\begin{array}{l}\text { Anand et } \\
\text { al }\end{array}$ & $\mathrm{n}=28$ & - & - & $\begin{array}{r}17 \\
(60.7)\end{array}$ & $2(7.1)$ \\
\hline $\begin{array}{l}\text { Berjano et } \\
\text { al }\end{array}$ & $\mathrm{n}=97$ & $9(9.3)$ & - & $3(3.1)$ & $4(4.1)$ \\
\hline Cahill et al & $\mathrm{n}=118$ & - & - & - & $2(1.7)^{*}$ \\
\hline $\begin{array}{l}\text { Cummock } \\
\text { et al }\end{array}$ & $\mathrm{n}=59$ & $23(39.0)$ & $14(23.7)$ & $\begin{array}{r}32 \\
(54.3)\end{array}$ & 0 \\
\hline $\begin{array}{l}\text { Dakwar et } \\
\text { al }\end{array}$ & $\mathrm{n}=25$ & - & - & $3(8.0)$ & 0 \\
\hline Isaacs et al & $\mathrm{n}=107$ & - & $33(30.8)$ & - & $3(2.8)$ \\
\hline $\begin{array}{l}\text { Kepler et } \\
\text { al }\end{array}$ & $\mathrm{n}=13$ & - & $3(23.1)$ & $1(7.7)$ & 0 \\
\hline $\begin{array}{l}\text { Knight et } \\
\text { al }\end{array}$ & $\mathrm{n}=58$ & - & - & $\begin{array}{r}6 \\
(10.3)^{\dagger}\end{array}$ & $2(3.4)$ \\
\hline $\begin{array}{l}\text { Lykissas et } \\
\text { al }\end{array}$ & $\mathrm{n}=451$ & $174(38.5)$ & - & $\begin{array}{r}171 \\
(38.0)\end{array}$ & $108(23.9)$ \\
\hline $\begin{array}{l}\text { Malham et } \\
\text { al }\end{array}$ & $\mathrm{n}=30$ & - & - & $5(16.7)$ & $1(3.3)$ \\
\hline $\begin{array}{l}\text { Moller et } \\
\text { al }\end{array}$ & $\mathrm{n}=53$ & $12(22.6)$ & - & $\begin{array}{r}13 \\
(24.5)\end{array}$ & 0 \\
\hline $\begin{array}{l}\text { Oliveira et } \\
\text { al }\end{array}$ & $\mathrm{n}=21$ & - & $3(14.3)$ & - & 0 \\
\hline $\begin{array}{l}\text { Pimenta et } \\
\text { al }\end{array}$ & $\mathrm{n}=36$ & - & $5(13.9)$ & $3(8.3)$ & $1(2.8)$ \\
\hline $\begin{array}{l}\text { Pumberger } \\
\text { et al }\end{array}$ & $\mathrm{n}=235$ & $101(43.0)$ & $32(13.6)$ & $\begin{array}{r}70 \\
(29.8)\end{array}$ & $12(5.1)$ \\
\hline $\begin{array}{l}\text { Rodgers et } \\
\text { al }\end{array}$ & $\mathrm{n}=600$ & - & - & - & $4(0.7)$ \\
\hline $\begin{array}{l}\text { Rodgers et } \\
\text { al }\end{array}$ & $\mathrm{n}=100$ & - & - & - & $1(1.0)$ \\
\hline $\begin{array}{l}\text { Rodgers et } \\
\text { al }\end{array}$ & $\mathrm{n}=313$ & - & - & - & $4(1.3)$ \\
\hline $\begin{array}{l}\text { Sharma et } \\
\text { al }\end{array}$ & $\mathrm{n}=43$ & $15(34.9)$ & $11(25.6)$ & - & $4(9.3)$ \\
\hline $\begin{array}{l}\text { Sofianos et } \\
\text { al }\end{array}$ & $\mathrm{n}=45$ & - & $10(22.2)$ & $8(17.8)$ & $6(13.3)$ \\
\hline $\begin{array}{l}\text { Tohmeh et } \\
\text { al }\end{array}$ & $\mathrm{n}=102$ & - & $28(27.5)$ & $\begin{array}{r}18 \\
(17.6)\end{array}$ & $3(1.0)$ \\
\hline Uribe et al & $\mathrm{n}=323$ & - & $91(28.2)$ & $\begin{array}{r}38 \\
(11.8)\end{array}$ & $13(4.0)$ \\
\hline $\begin{array}{l}\text { Waddell et } \\
\text { al }\end{array}$ & $\mathrm{n}=21$ & $3(14.3)$ & - & - & $3(14.3)$ \\
\hline Wang et al & $\mathrm{n}=23$ & $5(21.7)$ & - & $6(26.1)$ & 0 \\
\hline
\end{tabular}


postoperative lower extremity symptoms?

Six studies reported significant risk factors associated with lower extremity symptoms. ${ }^{14-17,30,32}$ Three of these studies reported patient risk factors associated with postoperative lower extremity symptoms. ${ }^{14,17,30}$ The Pumberger study reported patient risk factors from a multivariate regression analysis for psoas mechanical flexion deficit and lumbar plexus related motor deficits after lateral interbody fusion. Results from this analysis revealed gender to be associated with psoas mechanical flexion deficits, with female patients nearly 4 times as likely $(\mathrm{OR}=3.86$; $95 \% \mathrm{CI}$ : $1.10-13.5, p=0.03$ ) to develop psoas mechanical flexion deficits than males. The Isaacs study showed that the presence of at least one comorbidity affected the incidence of developing a major postoperative complication $(p=0.03)$. The Lykissas study showed that age was an independent risk factor for the development of both postoperative sensory deficits $(\mathrm{aOR}=0.975,95 \% \mathrm{CI}: 0.955-0.995, \mathrm{p}=0.01)$ and motor deficits (aOR=1.026, 95\% CI: 1.003-1.049, $\mathrm{p}=0.03$ ) from a multivariate regression analysis. In addition, age was an independent risk factor for persistent sensory deficits at final follow up $(\mathrm{aOR}=0.972$, 95\%CI=0.949-0.995, $\mathrm{p}=0.02$ ).

The 2010 Rodgers study ${ }^{15}$ reported disease risk factors from a multivariate logistic regression analysis for risk of complications after XLIF. The study showed that primary diagnosis was the only variable to significantly affect whether any complication occurred postoperatively $(p<0.01)$. A higher complication rate was seen in patients with primary diagnoses of degenerative disc disease and recurrent disc herniation, while the lowest complication rate was seen in patients diagnosed primarily with spinal stenosis or acquired spondylolisthesis.

Five studies reported surgical risk factors from multivariate models for lower extremity symptoms after lateral interbody fusion. . $^{14,16,17,32,37}$ The Isaacs study reported only length of surgery as an independent risk factor for the development of lower extremity weakness postoperatively $(p=0.03)$. Interestingly, inclusion of the L4-5 disc space $(p=0.70)$ and number of levels treated $(p=0.21)$ were not associated with the development of postoperative symptoms. The Pumberger study reported duration of surgery as the only independent risk factor for the development of psoas mechanical flexion deficit $(\mathrm{OR}=1.00 ; 95 \% \mathrm{CI}$ : $1.00-1.01, p=0.03)$. Duration of surgery was also the only independent risk factor associated with lumbar plexus related motor deficits $(\mathrm{OR}=1.01,95 \% \mathrm{CI}$ : $1.01-1.01, p=0.01$ ) over a 12-month period. The authors also mention an increased odds ratio for both psoas mechanical flexion deficits and lumbar plexus motor deficits when L4-5 was included, however this was not statistically significant $(p=0.17$ and $p=0.15$, respectively). The Rodgers study (2011) found inclusion of the L4-5 disc space to be an independent risk factor for developing any complication postoperatively $(\mathrm{p}<0.02)$. The Lykissas study reported both inclusion of the L4-5 disc space (aOR=1.77, 95\%CI: 1.012-3.109, $\mathrm{p}<0.05)$ and length of surgery $(\mathrm{aOR}=0.997,95 \% \mathrm{CI}=0.995-1.000, \mathrm{p}=.019)$ as independent risk factors for developing postoperative sensory deficits. Finally, Uribe et al identified a significant difference in psoas retraction time between patients with postoperative symptomatic neuropraxia and those without (32.3 minutes versus 22.6 minutes, $\mathrm{p}=0.031$ ), despite similar retraction blade stimulation thresholds in both groups. Stepwise logistic regression showed a significant positive relationship between the presence of symptomatic neuropraxia and total retraction time $(\mathrm{p}<0.001)$.

What are the long-term consequences of postoperative lower extremity symptoms?

Ten studies addressed the long-term consequences and patient outcomes of lower extremity symptoms after lateral interbody fusion (Figure 2). 13,14,17,21,24,26,28,30,31,36 Cummock et al performed a Kaplan-Meier survival analysis of postoperative thigh symptoms, which showed that as of day 365 postoperatively, $5.5 \%(3 / 59)$ of patients remained with thigh pain and $7 \%(4 / 59)$ with thigh numbness. Pumberger et al reported 15.7\% (37/235) of patients with lower extremity symptoms at 6 months follow up, and 7.2\% (17/235) had persistent symptoms at 12 months. Of the 37 patients with persistent symptoms at 6 months, 14 experienced sensory deficits, 9 with anterior thigh or groin pain, 7 with psoas mechanical flexion deficits, and 7 with lumbar plexus related motor deficits. Moller et al reported only $84 \%$ of patients symptom-free at 6 months follow-up. One patient in the study reported persistent symptoms 2 years post-

Downloaded from http://ijssurgery.com/ by guest on April 25, 2023 
operatively, however, these could not be detected on physical exam. Cahill et al reported $0.8 \%(1 / 118)$ of patients with persistent symptoms at 9 months follow up. This patient was noted to have new grade $3 / 5$ weakness in ipsilateral iliopsoas and grade $1 / 5$ weakness in ipsilateral quadriceps, which was persistent at 9 months follow-up and due to femoral nerve injury. Malham et al reported 6.7\% (2/30) of patients with persistent symptoms at 6 months follow up. One of the cases was a new motor deficit due to a posteriorly placed cage resulting in an L2 radiculopathy and grade $4 / 5$ weakness in ipsilateral quadriceps. The symptoms only partially resolved by 12 months follow-up. Lykissas et al reported 56.8\% (256/451) of patients with persistent symptoms at 6 months follow up, including 43 patients with anterior thigh pain, 127 with sensory deficits, and 86 with motor deficits. Of these patients, 5.9\% (15/256) had symptoms at least 18 months out from surgery. Sofianos et al reported $33.3 \%$ of patients (15/45) with symptoms persistent at least 9 months removed from surgery, including 5 patients with persistent hip flexion weakness at 11 months follow up, 7 with sensory deficits at 9 months, and 3 with neurologic deficits at 11 months. Isaacs et al (4.7\% of patients at 6 months), Knight et al (1.7\% at 12 months), and Sharma et al (4.7\% at 12 months) also reported the incidence of persistent lower extremity symptoms.

\section{Evidence Summary}

With respect to the incidence of lower-extremity symptoms after lateral interbody fusion, the risk is $0 \%$ to $60.7 \%$. However, due to low levels of evidence and inconsistency of results the overall strength of evidence is "low", that is we have low confidence that the evidence reflects the true effect and further re-

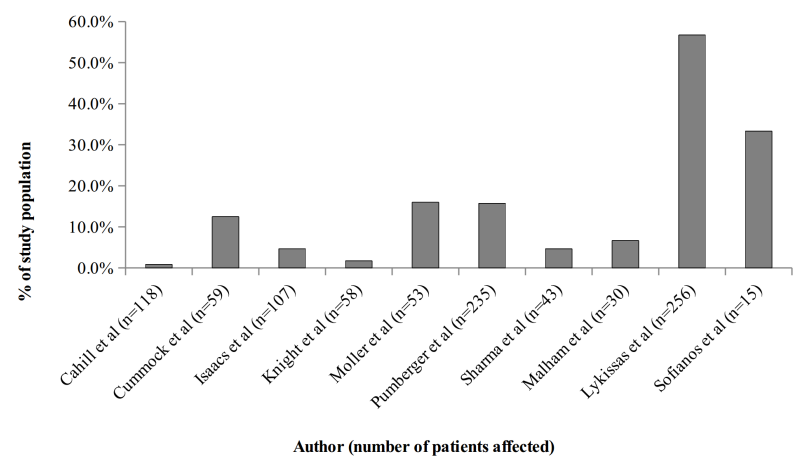

Fig. 2. Persistent lower extremity symptoms at 6 months follow-up. search is very likely to impact our confidence in the estimate of effect, and is likely to change the estimates.

With respect to patient risk factors for lower extremity symptoms after lateral interbody fusion, female patients are nearly 4 times as likely to develop psoas mechanical flexion deficits as males. Also, the presence of at least one comorbid condition was found to affect the incidence of developing major postoperative complications. In addition, age is associated with an increased risk of sensory and motor deficits in the postoperative period and over long-term follow up. However, since each of these associations is based on only one study, the strength of evidence for each finding is "low".

With respect to disease factors, primary diagnosis was found to significantly affect whether a complication occurred postoperatively; however, since this is based on only one study, the strength of evidence is "low".

With respect to surgical factors, duration of surgery was found to be an independent risk factor for development of psoas mechanical flexion deficit, lumbar plexus related motor deficits, and sensory deficits postoperatively. In addition, inclusion of the L4-5 disc space was found to be an independent risk factor for development of any postoperative complication, including sensory deficits. The strength of evidence is "high." That is, we have high confidence that our estimates represent the true effect and further research is unlikely to change our estimates of the effect. Psoas retraction time was also found to be associated with the development of postoperative neurologic deficit, however, the strength of evidence supporting this association is low since it is based on only one study's findings.

With respect to long-term consequences of postoperative lower extremity symptoms, the estimates are broad, ranging from $1.7 \%$ to $56.8 \%$ of patients with symptoms at 6 months follow up. Due to the inconsistency of results and low levels of evidence, the strength of evidence is "low." 


\section{Discussion}

With the aging of the U.S. population degenerative lumbar spine disease has been increasing in prevalence and is now one of the most commonly treated orthopedic conditions. Since 2001 there has been a $70 \%$ rise in spinal fusion procedure volume in the United States. ${ }^{38}$ Patients with this condition have traditionally been treated with lumbar spinal fusion via either an anterior, posterior, or combined approach. While this procedure is associated with excellent improvement in patient pain and disability, there are a host of potential complications and limitations, such as bowel perforation, major vessel injury and incidental durotomy, leading to a complication rate between $11 \%$ and $24 \%$ and additional unplanned surgeries in up to $12 \%$ of cases. ${ }^{39}$

Lateral transpsoas interbody fusion was introduced amidst the growing popularity of minimally invasive surgical techniques over the last two decades. ${ }^{40} \mathrm{Sev}$ eral popular systems are now offered, many of which utilize intraoperative EMG technology to assess proximity to neural structures. This approach offers numerous benefits over the traditional open approach to lumbar interbody fusion, owing in large part to avoidance of peritoneal violation, lack of extensive spinal muscle stripping, sparing of normal stabilizing elements of the spine (anterior and posterior longitudinal ligaments) and the minimally invasive nature of the technique. Furthermore, fusion rates and improvement in patient satisfaction have been on par with open techniques, ranging from $91-97 \%$ and $90 \%$, respectively. ${ }^{41,42}$

Despite the many benefits of this technique, it is far from a panacea for patients with lumbar degenerative pathology and is limited in several ways. Access to the L5-S1 disc space is limited given its location below the aortic bifurcation, which would require extensive vessel dissection. Also the presence of the sacrum and pelvis at this level renders it inaccessible without the creation of an iliac "window." In addition, many studies have mapped the intrapsoas neural anatomy and a confluence of nerves exists lateral to the L4-5 disc space including the femoral, genitofemoral, ilioinguinal and iliohypogastric nerves, which are all at risk for injury during this proce- dure..$^{4-6}$ Finally, this technique relies on indirect foraminal decompression via distraction of the disc space rather than direct decompression with laminectomy, which is often performed as part of posterior spinal fusion. The technique also has its own set of distinct complications related to traversing the psoas muscle, which is the focus of this review.

Our review revealed several important findings relating to postoperative complications. The most ubiquitous complication reported in the literature is postoperative thigh pain, which was present in up to $60.7 \%$ of patients. Many authors attribute this complication to an edematous reaction related to manipulation of the psoas muscle and is viewed as a minor complication. ${ }^{31}$ Indeed, many authors fail to report the incidence of this complication since most cases are transient in nature. ${ }^{16}$ However, it must be emphasized that these complications may not be transient in all cases, as our review showed $1.7 \%$ to $56.8 \%$ of patients may present with persistent symptoms at least 6 months out from surgery and more than 12 months removed in some cases. In addition, while it may be convenient to educate patients to expect thigh pain following surgery, this explanation may be limited in scope and further elaboration on what symptoms to expect is necessary for proper patient education. Our review revealed that the incidence of any complication occurring ranged up to $60.7 \%$, most commonly sensory disturbances, followed by thigh pain in up to $43 \%$, and hip flexion weakness in up to $30.8 \%$. While these complications are transient in most cases, and the vast majority will improve by 6 months follow up, it is important to emphasize the risk for more serious long-term complications due to femoral and lumbar nerve root injury, resulting in neurological deficits in up to $23.9 \%$ of patients. We were also able to elucidate risk factors associated with this procedure with a high level of confidence. We have shown that duration of surgery and inclusion of the L4-5 disc space are independent risk factors for the development of postoperative complications. This has multiple implications. First, given the steep learning curve for this procedure, inexperienced surgeons may require longer operative times until they are more comfortable with this technique. It may be appropriate for inexperienced surgeons to familiarize themselves with

Downloaded from http://ijssurgery.com/ by guest on April 25, 2023 
the approach beforehand and assist in multiple procedures in order to reduce their operative times and rate of complications. While no studies defined specific cut-off time points at which the risk of symptoms increases, our review has found that operative time ranged from 165 minutes to 178 minutes in studies reporting duration of surgery as a significant risk factor associated with complications. To the extent that this represents a reliable cut-off point above which the risk of symptoms increases, it may be beneficial to use this cut-off point as a guide in preoperative surgical planning. Furthermore, while not supported by data, it is reasonable to suspect that increasing surgical duration is associated with longer psoas retraction times, a risk factor for postoperative neuropraxia. Uribe et al found a significant positive relationship between the presence of a neurologic deficit and total retraction time. The authors recommend monitoring EMG for increasing thresholds during prolonged retraction times in an effort to reduce the incidence of complications. ${ }^{32}$ Inclusion of the L4-5 disc space has been implicated in many cases of postoperative complications and it is easy to understand why, given the confluence of major neural structures at this location. Prudent use of neural monitoring is all the more important with inclusion of this disc space, and the psoas should be parted between the middle and anterior third of the muscle, ensuring that nerves of the lumbar plexus are located posteriorly and out of the surgical corridor.

While our study focuses on lower extremity symptoms associated with this procedure, it is important to consider other complications reported in the literature. Vertebral body fracture occurred in $0.96 \%-15 \%$ of reported cases, cage subsidence in $1.2 \%-18.2 \%$, and abdominal wall paresis in $1.8 \%-5.1 \%$. $15,16,20-23,25,34,43-50$ Concerning abdominal dissection, many authors recommend the use of blunt dissection over electrocautery, which has been associated with increased risk of paresis. ${ }^{43}$ In addition, Tohmeh et al reported on 2 cases of peritoneal perforation, which has the potential to go unnoticed given the limited visualization with this procedure, so care should be taken when sweeping the peritoneum anteriorly and in placing the dilators.

There are several limitations of this review including the significant heterogeneity in the selected studies with respect to sample size and diagnosis. A metaanalysis was considered to address the apparent heterogeneity, however, due to the significant variability in study quality, and paucity of high quality prospective studies (only three level I studies) on this topic reported in the literature, we decided against this methodology. It is important for the reader to note that variability in surgical technique between studies incorporates an additional confounding variable and should be considered in the context of this review's findings. Three high quality studies varied from the rest in terms of their inconsistent use of intraoperative neuromonitoring (Pumberger et al. ${ }^{14}$ and Knight et al. ${ }^{36}$ ) and anterior plate fixation (Isaacs et al. ${ }^{37}$ ), which may diminish the accuracy of this review's findings. In addition, other potential confounding factors such as retraction time, retractor opening size, bed flexion, and adherence to non-muscular pharmaco-blockade were not reported by the studies included in this review but should also be considered when interpreting these findings. Regarding the novelty of this study's findings, there have been few review articles and meta-analyses published on related topics, including direct nerve injury after LTIF; however, a systematic review of nerve injury and transient thigh pain after LTIF is lacking, and we believe the comprehensive overview and recommendations contained herein will bolster surgeons' knowledge and understanding of complications associated with this popular technique.

\section{Conclusion}

The lateral transpsoas approach is a popular minimally invasive technique for achieving spinal fusion in patients with degenerative lumbar spine disease. The literature is replete with studies reporting postoperative complications of this procedure including transient lower extremity sensory changes and lumbar nerve root injury. Numerous risk factors were also identified including lengthier duration of surgery and inclusion of L4-5 intervertebral disc space. While most patients experienced transient symptoms, the occurrence of long term postoperative complications is not uncommon. Future high-quality research focused on risk reduction strategies may improve complication rates associated with this proce- 
dure.

\section{References}

1. McAfee PC, Regan JJ, Geis WP, Fedder IL. Minimally invasive anterior retroperitoneal approach to the lumbar spine. Emphasis on the lateral BAK. Spine (Phila Pa 1976). 1998;23(13):1476-1484.

2. Bergey DL, Villavicencio AT, Goldstein T, Regan JJ. Endoscopic lateral transpsoas approach to the lumbar spine. Spine (Phila Pa 1976). 2004;29(15):1681-1688.

3. Ozgur BM, Aryan HE, Pimenta L, Taylor WR. Extreme Lateral Interbody Fusion (XLIF): a novel surgical technique for anterior lumbar interbody fusion. Spine J. 2006;6(4):435-443.

4. Banagan K, Gelb D, Poelstra K, Ludwig S. Anatomic mapping of lumbar nerve roots during a direct lateral transpsoas approach to the spine: a cadaveric study. Spine (Phila Pa 1976).

2011;36(11):E687-E691.

5. Benglis DM. Vanni S. Levi A, Benglis DM, Vanni $\mathrm{S}$, Levi AD. An anatomical study of the lumbosacral plexus as related to the minimally invasive transpsoas approach to the lumbar spine. J Neurosurg Spine. 2009;10(2):139-144.

6. Guérin P, Obeid I, Bourghli A, et al. The lumbosacral plexus: anatomic considerations for minimally invasive retroperitoneal transpsoas approach. Surg Radiol Anat. 2012;34(2):151-157.

7. Park DK, Lee MJ, Lin EL, Singh K, An HS, Phillips FM. The relationship of intrapsoas nerves during a transpsoas approach to the lumbar spine: anatomic study. J Spinal Disord Tech.

2010;23(4):223-228.

8. Moher D, Liberati A, Tetzlaff J, Altman DG. Preferred reporting items for systematic reviews and meta-analyses: the PRISMA statement. PLoS Med. 2009;6(7):e1000097.

9. Jour- T, Journal T, Sur- J. Introducing Levels of Evidence to The Journal Deputy Editor for Outcome Studies. 2003.

10. Norvell DC, Dettori JR, Fehlings MG, Fourney DR, Chapman JR. Methodology for the systematic reviews on an evidence-based approach for the management of chronic low back pain. Spine (Phila Pa 1976). 2011;36(21 Suppl):S10-S18.
11. Atkins $\mathrm{D}$, Best $\mathrm{D}$, Briss PA et al. Education and debate. BMJ. 2004;328:1-8.

12. Dettori JR, Norvell DC, Dekutoski M, Fisher C, Chapman JR. Methods for the systematic reviews on patient safety during spine surgery. Spine (Phila $\mathrm{Pa}$ 1976). 2010;35(9 Suppl):S22-S27.

13. Cummock MD, Vanni S, Levi AD, Yu Y, Wang MY, Cummock MD. Vanni S. Levi AD. Yu Y. Wang M. An analysis of postoperative thigh symptoms after minimally invasive transpsoas interbody fusion. $J$ Neurosurg Spine. 2011;15(1):11-18.

14. Pumberger M, Hughes AP, Huang RR, Sama AA, Cammisa FP, Girardi FP. Neurologic deficit following lateral lumbar interbody fusion. Eur Spine $J$. 2012;21(6):1192-1199.

15. Rodgers WB, Cox CS, Gerber EJ. Early complications of extreme lateral interbody fusion in the obese. J Spinal Disord Tech. 2010;23(6):393-397.

16. Rodgers WB, Gerber EJ, Patterson J. Intraoperative and early postoperative complications in extreme lateral interbody fusion: an analysis of 600 cases. Spine (Phila Pa 1976). 2011;36(1):26-32.

17. Lykissas MG, Aichmair A, Hughes AP, et al. Nerve injury after lateral lumbar interbody fusion: a review of 919 treated levels with identification of risk factors. Spine J. 2014;14(5):749-758.

18. Anand N, Baron EM, Thaiyananthan G, Khalsa K, Goldstein TB. Minimally invasive multilevel percutaneous correction and fusion for adult lumbar degenerative scoliosis: a technique and feasibility study. J Spinal Disord Tech. 2008;21(7):459-467.

19. Anand N, Rosemann R, Khalsa B, Baron EM. Mid-term to long-term clinical and functional outcomes of minimally invasive correction and fusion for adults with scoliosis. Neurosurg Focus.

2010;28(3):E6.

20. Berjano P, Balsano M, Buric J, Petruzzi M, Lamartina C. Direct lateral access lumbar and thoracolumbar fusion: preliminary results. Eur Spine J. 2012;21 Suppl 1:S37-S42.

21. Cahill KS, Martinez JL, Wang MY, Vanni S, Levi AD. Motor nerve injuries following the minimally invasive lateral transpsoas approach. J Neurosurg Spine. 2012.

22. Dakwar E, Cardona RF, Smith DA, Uribe JS. Early outcomes and safety of the minimally invasive, lateral retroperitoneal transpsoas approach for adult 
degenerative scoliosis. Neurosurg Focus.

2010;28(3):E8.

23. Kepler CK, Sharma AK, Huang RC. Lateral transpsoas interbody fusion (LTIF) with plate fixation and unilateral pedicle screws: a preliminary report. J Spinal Disord Tech. 2011;24(6):363-367.

24. Malham GM, Ellis NJ, Parker RM, Seex KA. Clinical outcome and fusion rates after the first 30 extreme lateral interbody fusions. Scientific World Journal. 2012;2012:246989.

25. Rodgers WB, Cox CS, Gerber EJ. Minimally Invasive Treatment (XLIF) of Adjacent Segment Disease after prior Lumbar Fusions. Internet J Minim Invasive Spinal Technol. 2009;3(4).

26. Sharma AK, Kepler CK, Girardi FP, Cammisa FP, Huang RC, Sama AA. Lateral lumbar interbody fusion: clinical and radiographic outcomes at 1 year: a preliminary report. J Spinal Disord Tech.

2011;24(4):242-250.

27. Wang MY, Mummaneni P V, Wang MY. Mummaneni P. Minimally invasive surgery for thoracolumbar spinal deformity: initial clinical experience with clinical and radiographic outcomes. Neurosurg Focus. 2010;28(3):E9.

28. Sofianos DA, Briseño MR, Abrams J, Patel AA. Complications of the lateral transpsoas approach for lumbar interbody arthrodesis: a case series and literature review. Clin Orthop Relat Res.

2012;470(6):1621-1632.

29. Waddell B, Briski D, Qadir R, et al. Lateral lumbar interbody fusion for the correction of spondylolisthesis and adult degenerative scoliosis in highrisk patients: early radiographic results and complications. Ochsner J. 2014;14(1):23-31.

30. Isaacs RE, Hyde J, Goodrich JA, Rodgers WB, Phillips FM. A prospective, nonrandomized, multicenter evaluation of extreme lateral interbody fusion for the treatment of adult degenerative scoliosis: perioperative outcomes and complications. Spine (Phila Pa 1976). 2010;35(26 Suppl):S322-S330.

31. Moller DJ, Slimack NP, Acosta FL, Koski TR, Fessler RG, Liu JC. Minimally invasive lateral lumbar interbody fusion and transpsoas approach-related morbidity. Neurosurg Focus. 2011;31(4):E4.

32. Uribe JS, Isaacs RE, Youssef JA, et al. Can triggered electromyography monitoring throughout retraction predict postoperative symptomatic neuro- praxia after XLIF? Results from a prospective multicenter trial. Eur Spine J. 2015;24 Suppl 3:378-385. 33. Pimenta L, Oliveira L, Schaffa T, Coutinho E, Marchi L. Lumbar total disc replacement from an extreme lateral approach: clinical experience with a minimum of 2 years' follow-up. J Neurosurg Spine. 2011;14(1):38-45.

34. Tohmeh AG, Rodgers WB, Peterson MD. Dynamically evoked, discrete-threshold electromyography in the extreme lateral interbody fusion approach. J Neurosurg Spine. 2011;14(1):31-37.

35. Oliveira L, Marchi L, Coutinho E, Pimenta L. A radiographic assessment of the ability of the extreme lateral interbody fusion procedure to indirectly decompress the neural elements. Spine (Phila Pa 1976). 2010;35(26 Suppl):S331-S337.

36. Knight RQ, Schwaegler P, Hanscom D, Roh J. Direct lateral lumbar interbody fusion for degenerative conditions: early complication profile. J Spinal Disord Tech. 2009;22(1):34-37.

37. Isaacs RE, Hyde J, Goodrich JA, Rodgers WB, Phillips FM. A prospective, nonrandomized, multicenter evaluation of extreme lateral interbody fusion for the treatment of adult degenerative scoliosis: perioperative outcomes and complications. Spine (Phila Pa 1976). 2010;35(26 Suppl):S322-S330.

38. Weiss AJ, Elixhauser A. Trends in Operating Room Procedures in U.S. Hospitals, 2001-2011 Statistical Brief \#171. HCUP. 2014.

39. Phillips FM, Slosar PJ, Youssef JA, Andersson G, Papatheofanis F. Lumbar spine fusion for chronic low back pain due to degenerative disc disease: a systematic review. Spine (Phila Pa 1976). 2013;38(7):E409-E422.

40. Ozgur BM, Aryan HE, Pimenta L, Taylor WR. Extreme Lateral Interbody Fusion (XLIF): a novel surgical technique for anterior lumbar interbody fusion. Spine J. 2006;6(4):435-443.

41. Rodgers WB, Gerber EJ, Patterson JR. Fusion after minimally disruptive anterior lumbar interbody fusion: Analysis of extreme lateral interbody fusion by computed tomography. $S A S J .2010 ; 4(2): 63-66$. 42. Ozgur BM, Agarwal V, Nail E, Pimenta L. Twoyear clinical and radiographic success of minimally invasive lateral transpsoas approach for the treatment of degenerative lumbar conditions. $S A S J$. 2010;4(2):41-46. 
43. Dakwar E, Le T V, Baaj AA, et al. Abdominal wall paresis as a complication of minimally invasive lateral transpsoas interbody fusion. Neurosurg Focus. 2011;31(4):E18.

44. Karikari IO, Grossi PM, Nimjee SM, et al. Minimally invasive lumbar interbody fusion in patients older than 70 years of age: analysis of peri- and postoperative complications. Neurosurgery.

2011;68(4):897-902; discussion 902.

45. Brier-Jones JE, Palmer DK, Inceoğlu S, Cheng

WK. Vertebral body fractures after transpsoas interbody fusion procedures. Spine $J$.

2011;11(11):1068-1072.

46. Le T V, Baaj AA, Dakwar E, et al. Subsidence of polyetheretherketone intervertebral cages in minimally invasive lateral retroperitoneal transpsoas lumbar interbody fusion. Spine (Phila Pa 1976).

2012;37(14):1268-1273.

47. Le T V, Smith DA, Greenberg MS, Dakwar E, Baaj AA, Uribe JS. Complications of lateral plating in the minimally invasive lateral transpsoas approach. $J$ Neurosurg Spine. 2012;16(3):302-307.

48. Marchi L, Oliveira L, Amaral R, et al. Lateral interbody fusion for treatment of discogenic low back pain: minimally invasive surgical techniques. $A d v \mathrm{Or}$ thop. 2012;2012:282068.

49. Marchi L; A, Abdala N, Oliveira L, Amaral R,
Coutinho E, Pimenta L. Stand-alone lateral interbody fusion for the treatment of low-grade degenerative spondylolisthesis. Scientific World Journal. 2012;2012:456346.

50. Rodgers WB, Lehmen JA, Gerber EJ, Rodgers JA. Grade 2 spondylolisthesis at L4-5 treated by XLIF: safety and midterm results in the "worst case scenario". Scientific World Journal.

2012;2012:356712.

\section{Disclosures}

The authors declare no relevant disclosures.

\section{Corresponding Author}

Jeffrey M. Spivak, MD, Director, Spine Center, NYU Hospital for Joint Diseases, Department of Orthopaedic Surgery, 301 East 17th Street, New York NY 10003. Jeffrey.Spivak@nyumc.org. Published 12 November 2015.

This manuscript is generously published free of charge by ISASS, the International Society for the Advancement of Spine Surgery. Copyright $\odot 2015$ ISASS. To see more or order reprints or permissions, see http://ijssurgery.com. 